\title{
Correction to: Evaluation of SWAT performance in modeling nutrients of Awash River basin, Ethiopia
}

\author{
Amare Shiberu Keraga $^{1}\left[{ }^{\circ} \cdot\right.$ Zebene Kiflie $^{1} \cdot$ Agizew Nigussie Engida $^{2}$
}

Published online: 28 November 2018

C) Springer Nature Switzerland AG 2018

\section{Correction to: Modeling Earth Systems and Environment https://doi.org/10.1007/s40808-018-0533-y}

In the 'Materials and methods' and in the 'Results and discussion' sections, there are errors that confuse readers in the scientific community.

1. In 'Materials and methods' section: ' $\mathrm{N}, \mathrm{P}$ ' in the 'Output response' column of Table 1 (page 6), except that of RSR, should go to the next line down. In other words, the performance ratings of $\mathrm{R}^{2}$ and NSE $\left(\mathrm{R}^{2}>0.70, \ldots\right.$ and $0.65<\mathrm{NSE} \leq 1.0, \ldots)$ refers only to $\mathrm{N}, \mathrm{P}$ and hence they (N, P and their respective ratings) need to be in one row.

The table (Table 1) should look like:

2. In the 'Results and discussion' section: the paragraphs are wrongly placed that affect the idea flow for readers in the scientific community

The paragraphs, therefore, should read:

\section{Results and discussion}

\section{Quantification of the SWAT model performance}

Performance of flow of the model output was seen first and those of nutrients (nitrogen and phosphorus) were

The original article can be found online at https://doi.org/10.1007/ s40808-018-0533-y.

Amare Shiberu Keraga

amare.shiberu@aau.edu.et

1 School of Chemical and Bio-Engineering, Addis Ababa University, P.O. Box 385, Addis Ababa, Ethiopia

2 School of Civil and Environmental Engineering, Addis Ababa University, P.O. Box 385, Addis Ababa, Ethiopia considered next. For both flow and nutrients, sensitive parameters were identified before calibration and validation of their outputs by the model.

\section{Sensitivity analysis of flow}

Nineteen hydrologic parameters that might have influences on stream flow of Awash River were used in the sensitivity analysis. The model parameters, their definition, initial ranges of the parameters, $t$ stat, $p$ values and their sensitivity ranks were given in Table 2. The rank was assigned with respect to absolute values of $t$ stat and $p$ values in the grid from the global SA according to Khalid et al. (2016). Parameters of larger $t$ Stat in absolute values or those of p-values less than or equal to 0.05 have been taken as those to which the model variable (stream flow) was most sensitive. On the basis of the $\mathrm{p}$ values, the first ten ranked (in the increasing order of sensitivity) parameters (Table 2) were therefore pointed out to be more sensitive, namely; GW_DELAY. gw, EPCO.bsn, RCHRG_DP.gw, ESCO.hru, GWQMN.gw, SOL_K (..).sol, SOL_BD(..).sol, SLSUBBSN.hru, HRU_ SLP.hru, and CN2.mgt. Hence, these parameters were found to be the most crucial parameters for the studied basin as they generally govern the surface hydrological processes and stream routing. The hydrology is observed to be exceptionally sensitive to curve number (CN2).

Monthly calibration, validation and uncertainty analysis of the river flow

The ten flow determining parameters identified as most sensitive were considered in the model calibration of the flow. The long term monthly observed flow data of 1997-2005 with three escape years (1994-1996) were used for automatic calibration of the stream flow at Dubti. The monthly simulated versus observed stream flow is also plotted in Fig. 3. Model efficiency during monthly calibration of the model flow simulation evaluated by $\mathrm{R}^{2}$, NSE and RSR 
Table 1 General performance ratings for recommended statistics in monthly time step

\begin{tabular}{|c|c|c|c|c|c|}
\hline \multirow{2}{*}{$\begin{array}{l}\text { Objective } \\
\text { function }\end{array}$} & \multirow[t]{2}{*}{ Output response } & \multicolumn{4}{|c|}{ Performance ratings } \\
\hline & & Very good & Good & Satisfactory & Unsatisfactory \\
\hline \multirow[t]{2}{*}{$\mathrm{R}^{2}$} & Streamflow & $0.85<\mathrm{R}^{2} \leq 1.0$ & $0.75<\mathrm{R}^{2} \leq 0.85$ & $0.60<\mathrm{R}^{2} \leq 0.75$ & $\mathrm{R}^{2} \leq 0.60$ \\
\hline & $\mathrm{N}, \mathrm{P}$ & $\mathrm{R}^{2}>0.70$ & $0.60<R^{2} \leq 0.70$ & $0.30<\mathrm{R}^{2} \leq 0.60$ & $\mathrm{R}^{2} \leq 0.30$ \\
\hline RSR & Streamflow, N, P & $0 \leq \mathrm{RSR} \leq 0.50$ & $0.50<\mathrm{RSR} \leq 0.60$ & $0.60<\mathrm{RSR} \leq 0.70$ & $\mathrm{RSR}>0.70$ \\
\hline \multirow[t]{2}{*}{ NSE } & Streamflow & $0.80<\mathrm{NSE} \leq 1.0$ & $0.70<\mathrm{NSE} \leq 0.80$ & $0.50<\mathrm{NSE} \leq 0.70$ & $\mathrm{NSE} \leq 0.50$ \\
\hline & $\mathrm{N}, \mathrm{P}$ & $0.65<\mathrm{NSE} \leq 1.0$ & $0.50<\mathrm{NSE} \leq 0.65$ & $0.35<\mathrm{NSE} \leq 0.50$ & $\mathrm{NSE} \leq 0.35$ \\
\hline
\end{tabular}

of stream flow were respectively $0.79,0.64$ and 0.60 as shown in Table 3, implying that the discrepancy between observed and predicted stream flow was less. Validation was performed by running the SWAT-CUP for dataset of time period 2006-2014, using the previously calibrated input parameters. Table 3 shows the monthly graphical performance evaluation of SWAT model during calibration and validation periods. The plot in Fig. 4 implies that the model simulation is best fitted with the observed flow measurement. During validation $0.81,0.52$, and 0.70 were obtained as the respective values of $\mathrm{R}^{2}$, NSE and RSR (Table 3). For monthly and watershed-scale hydrological models, Moriasi et al. (2015) and Moriasi et al. (2007) in their evaluation criteria for recommended statistical performance measures indicated in Table 1 suggested both for calibration and validation that NSE in the range of $(0.5,0.7]$ imply that a model is satisfactory.

Their suggestion of $\mathrm{R}^{2}$ in the range $(0.75,0.85]$ indicate that a model performance is good. Since performances of this study measured by NSE and $\mathrm{R}^{2}$ lie respectively in these ranges, the statistics were satisfactory and good. Similarly, RSR values of 0.60 and 0.70 generated, respectively, during calibration and validation of flow were also in permissible ranges as their ratings, as recommended by Moriasi et al. (2007), were good and satisfactory. According to the arguments by Moriasi et al. (2007) and Moriasi et al. (2015), the values of the objective functions of this study both in the calibration and validation periods indicated that the model's overall performance for flow was good and is in the acceptable limit.

Uncertainties might have been born either from the observed or from the predicted flows since abnormal patterns and deviations of the observed data from the corresponding months' simulated ones were seen, for instance, in Jan 2000, Aug 2000, Aug 2001, Aug 2002, Sep 2003, Apr 2004, Aug 2004, and Aug 2005. Some values of flow, e.g., increasing in Nov 1997, Sept 1999, Jan 2000, April 2004, being dry seasons and decreasing in all years of June being wet seasons encountered both in the observed and predicted results were a bit far from expectations.

The reason for the mismatch of observed flows with the corresponding predicted ones might either be due to inaccurate measurement of discharge at the gauging station or due to the observed flow from the sudden discharge releases of the Tendaho dam just upstream of the station, which stores water during the rainy season and releases afterwards as required. However, errors from the predicted flow might be attributed to inaccuracies in the rainfall data used in setting up the model. Generally, the model simulation is seen to give higher values of flow than the observed ones.

Uncertainty at Dubti gauging station depicted that the 95PPU seems to be poor for the monthly time series simulation of discharge since only about $46 \%$ of the observed stream flow was bracketed by the 95PPU band (Table 3). Though bracketing of the observed data by the 95ppu seems to be somehow far from the ideal expectation of unity, thickness of the band confirmed by the $r$-factor value of 0.52 (a bit close to zero) is relatively good. This implies that the model is within the acceptable range of uncertainty since it is compromised by good NSE and $\mathrm{R}^{2}$ values. $\mathrm{p}$-factor could be made as close to 1 as possible at the expense of $r$-factor by repeating the iteration but such actions have risks of reducing values of $\mathrm{R}^{2}$ and NSE sometimes. 